\title{
Adopting Knowledge Discovery in Databases for Customer Relationship Management in Egyptian Public Banks
}

\author{
A. Khedr and J. N. Kok \\ Leiden University, Leiden Institute of Advanced Computer Science \\ P.O. Box 9512, 2300 RA Leiden, The Netherlands \\ Email: khedr@liacs.nl
}

\begin{abstract}
We propose a framework for studying the effect of KDD on CRM in the Egyptian banking sector. We believe that the KDD process and applications may perform a significant role in Egyptian banks to improve CRM, in particular for customer retention. Our believe is supported by the results of the field survey at the largest Egyptian bank. Keywords. Adopting new technology, Knowledge Discovery in Databases (KDD), Customer Relationship Management (CRM), and banking sector.
\end{abstract}

\section{Introduction}

Innovative technology is defined as any new developmental technology in organizations [1]. It can involve creating or reengineering products or services to meet the new market demand, introducing new technologies to improve productivity, developing or applying new marketing techniques to expand the sales opportunities, and incorporate the new forms of management systems and techniques to improve the operational efficiency [2].

As a result of the continuous increase of the business needs, the amount of data in database systems is growing fast. Since the cost of data storage is decreasing continuously, users tend to store all available information in the databases, to retain information that might be useful in the future, even if it is not of a direct value [3].

In the banking sector, the increasing competition, the deregulation, and the adoption of new technologies, have contributed to the growth of customer's power. Customers may switch the banks on a whim. To win the new customers and retain the existing ones, banks may adopt the Knowledge Discovery in Databases (KDD) for analyzing the customers' behaviors and the needs. In the banking sector of Western Europe and the United States, KDD has been widely adopted.

In this paper, we propose a framework for studying the effect of adopting KDD in the banking sector in Egypt. We present the results of the field survey, which support our belief in the validity of our proposal. The outline of this paper is as follows.

Please use the following format when citing this chapter:

Khedr, A., Kok, J.N., 2006, in IFIP International Federation for Information Processing, Volume 218 , Professional Practice in Artificial Intelligence, eds. J. Debenham, (Boston: Springer), pp. 201-208. 
Section 2 is about the adoption of new technology whereas section 3 presents a description of problems with adopting KDD in the banking sector in Egypt. Section 4 presents the results of a survey that we conducted in the Egyptian banking sector, to identify the causes and the solutions for the main problem. Section 5 describes the conceptual framework for adopting $\mathrm{KDD}$ and the ways of measuring the framework's variables. Section 6 concludes and points at future work.

\section{Adoption of new technology}

Stoneman [4] integrated the idea that adopting a new technology like KDD is similar to or the same as any other kind of investment under uncertainty and therefore can be analyzed and measured [5]. The investment decision of adopting the new technology is characterized by 1) uncertainty of the prospect profit, 2) irreversibility that creates at least some sunk costs, and 3) the opportunity of the delay. The primary implication of the way of looking at the adoption of any new technology' problem is that there is "option value" to waiting: that is, adoption should not take place the instant that benefits equal costs, but should be delayed until benefits are somewhat above costs [6].

Adoption of a new technology is often expensive for many reasons [6]. The observable determinants of the new technology adoption are the benefits gained by the user and the costs of adoption. These benefits are simply the difference in profits when an organization migrates from an older technology to a newer. In the case of customers, the benefits are the increased utility from the new product or service, but may also include such "non-economic" factors as the satisfaction of being the first on the block with a new product or service [6].

\section{The banking sector in Egypt}

During the last thirty-five years, two important changes have taken place in the Egyptian banking sector; one in the 1970s and one in the 1990s.

The first important change happened in the 1970 s, when competition among and between banks and financial service firms increased considerably. The increased competition has placed the new emphasis on the value of the customer retention. In relation to this phenomenon, Vitria [7] states, "the cost of acquiring the new customers continues to rise as the competition forces providers to offer increasingly better incentives. This encourages customers to move from service to service, without giving the banks a chance to recover their acquisition costs".

The second important change happened in 1991, when Egypt introduced an extensive Economic Reform and Structural Adjustment Program (ERSAP). The economy changed from an inward-looking centrally planned economy, dominated by the public sector, to an outward-looking economy led by the private sector. Liberalization and privatization of the financial sector in general and of the banking system in particular, were crucial to the intended transformation of the economy [8]. 
Egypt's transforming economy was following the same path as the globalization processes across the world. This worldwide globalization of financial markets has led to create strong relationships among financial institutions [9]. As a result, the financial institutions today face a fast-paced, dynamic, and competitive environment at a global scale. Given such a competitive environment, the financial services sector, as well as the financial institutions, is required to examine their performance because their survival depends on their productive efficiencies with their customers. Early studies (see, for example, Berger and Humphrey [10]; Berger, Hunter, and Timme [11]) demonstrated that in particular, in the banking sector, inefficiencies are more important than scale and scope issues.

The introduction of adoption new technology such as KDD in the Egyptian banking sector would require a different approach than the approach used in other countries because of the cultural, economic, and social differences as outlined in Figure 1 [12]. The provisional problem statement is as follows:

"There is a need for the banking sector in Egypt to adopt the new technologies to use available data in a more efficient way in order to manage customer relations; the present systems are time consuming and unreliable; knowledge discovery in databases could improve the customer relationship management and the customer retention in the banking sector in the country. Given the unique characteristics of the country a new approach will be needed for the introduction of KDD".

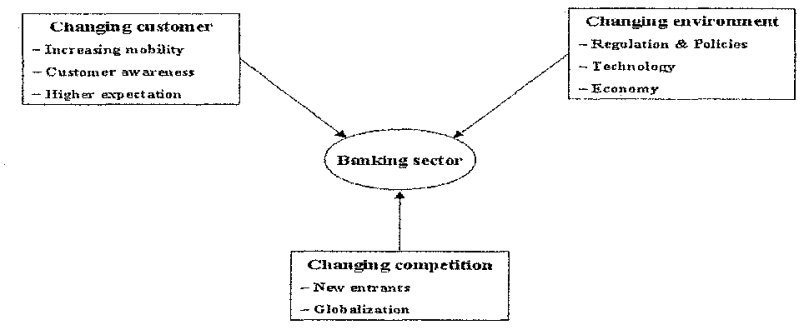

Figure 1: Factors influencing the Egyptian banking sector Source: Adopted from Tina Harrison, 2000

\section{Survey}

To identify the problems of the Egyptian banks, and which issues need to be resolved to remove the problem, we conducted a survey to study the current tools used by the Egyptian banking sector to achieve their strategies, and the main obstacles that this sector is facing to adopt KDD techniques. The survey was conducted among customers, CRM specialists, and IT specialists of one of the largest banks in Egypt:

- CRM department: All staff in the main building in Cairo branch, 28 samples. 
- Information technologies and computer centre department: All staff in the main building in Cairo branch, 30 samples.

- Employees (front end employees): All staff in the main branch in great Cairo, 172 samples.

- Customers/clients: 560 samples.

In the customer survey questionnaire (560 samples), the respondents were 472 samples divided into two groups, namely, the control group (236 samples) and the experimental group (236 samples).

Next, we will describe the survey results, focusing on the current situation in the bank, and the obstacles to adopt KDD techniques.

The customers' point of view: The survey analysis for the customers considered five aspects, namely interior design, reliability, responsiveness, assurance, and empathy.

For the interior design aspect we observed the following:

- Most of the customers are not satisfied with the interior design of their bank.

- Neither the bank's facilities and materials, nor the bank's employees, look representative for their bank.

For the reliability aspect we observed the following:

- The bank does not keep its promises to keep the customers.

- Lack of provided services with acceptable speed.

- Lack of interest in solving the customers' problems.

- Lack of information of the services offered to the customers.

For the responsiveness aspect we observed the following:

- The bank fails to inform the customers how much time is needed to perform certain services.

- The bank's employees fail to provide prompt services.

For the assurance aspect we observed the following:

- The bank's employees do not instill confidence.

- Customers feel safe and behave courteously when dealing with the bank.

For the empathy aspect we observed the following:

- The bank does not give individual attention to the customers.

- The bank's opening hours are inconvenient to the customers.

- The customers do not feel that their interests are at their banks' heart.

- The bank's employees do not always understand the customers' needs.

The CRM department's point of view: The CRM staff has complaints about the inaccuracy of the systems they use, the lack of user-friendliness of said systems, and the constant need for assistance from the IT staff. 
The IT department's point of view: The systems and applications currently in use are unable to provide all the necessary customer data and information in an adequate and accurate way.

Next, we present the survey results on the obstacles of adoption of KDD from the point of view of the CRM and IT departments. The CRM department is, in general, not acquainted with KDD. The IT department is not satisfied with the current level of service they deliver. The IT department strongly supports the application and use of modern techniques to improve their service level. Both departments listed the following seven obstacles to the incorporation of KDD:

- the lack of information on expected profitability;

- the lack of capital;

- the lack of information on customer needs and requirements;

- the lack of information on all services offered and accepted by customers;

- the lack of information on service quality standards and new markets;

- the lack of information on modern technologies; and

- the lack of qualified engineers, DW experts, managers, and consultants.

In summary, from the survey the following three conclusions can be drawn:

- Most of the bank's customers are neither satisfied in dealing with the bank, nor have any loyalty towards the bank. However, they feel safe in dealing with the bank.

- The CRM department employees are not satisfied with the existing service systems.

- The IT department is not satisfied with the existing service level they offer to other employees' bank. They fully support the new proposed techniques.

\section{Framework}

After identifying the main obstacles, a framework is proposed to investigate the effect of adopting KDD that can help the banking sector in Egypt to improve CRM, in particularly by increasing customer retention. The framework has the following three objectives:

1. To study the current status of methods and tools for analyzing and providing information through the existing system in Egyptian banks, to find the degree of adaptability to state-of the- art technology.

2. To explore how CRM may benefit from KDD.

3. To discuss how successful KDD can be measured.

We focus in detail on the effect of KDD on customer satisfaction in customer retention. The conceptual framework for customer retention as shown in Figure 2, 
investigates KDD as independent: by considering adaptation and impact of implementing KDD, as well as customer retention as dependent variable.

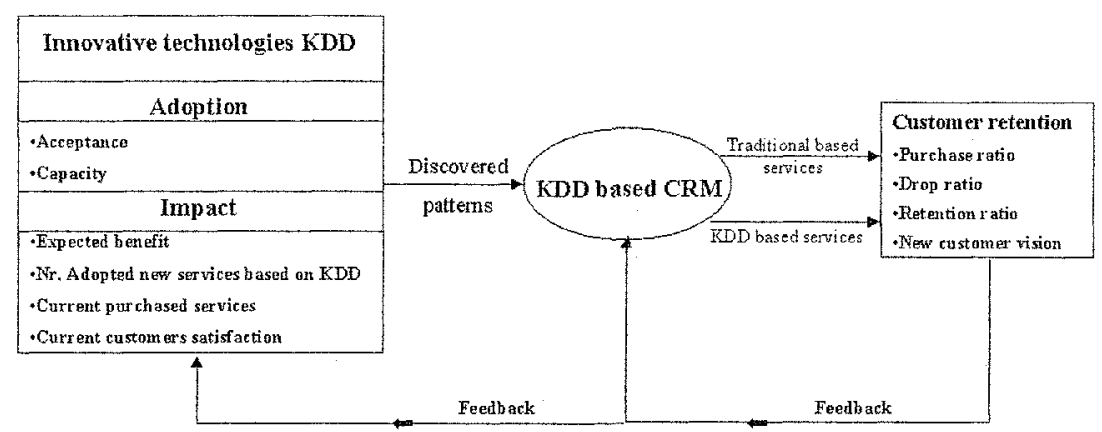

Figure 2: Conceptual framework

\section{Adoption}

The adopted technology is the way of how the users accept and use a technology. When users are presented with a new technology, two main factors influence their decision about how and when they will use it [13]:

- Acceptance: Acceptance measure is defined by Fred Davis as "the degree to which a person believes that using a particular system would enhance his or her job performance" and "the degree to which a person believes that using a particular system would be free from effort" [13]. Also it can be defined as a "perceived usefulness, perceived ease of use, and user acceptance of information technology" [13]. The acceptance measure considers two different groups of opinions: CRM staff department and IT staff department.

- Capacity: Capacity measure is defined in the present research as the bank capacity or ability to apply the new technology techniques (obstacles to the new techniques by CRM \& IT departments) from different aspects such as time effort consuming, fund, lack of information, and expertise. The acceptance factor considers two different groups opinions CRM staff department and IT staff department.

\section{Impact}

To measure the impact of implementing KDD, four different measurements are considered as following:

- Expected benefits: This measure describes the benefits gained by adopting KDD from different view of points CRM and IT staffs. 
- New services based on KDD: This measure describes the characteristics of the new services that offered by bank based on KDD.

- Current purchased services: This measure describes the characteristics of the current/exiting services that offered by bank according to the previous bank' CRM strategy.

- Customers' satisfaction: To measure the customer satifaction level in the bank the study investigate the customer satisaction from five differernt customer' views:

- the physical appearance,

- service level and reliability,

- employees' behaviour and attitude,

- assurance, and

- empathy.

\section{Customer retention}

We use five measurements of the dependent variable customer retention:

- Competitive advantage factors: This measure describes CRM and IT staffs' views of competitive advantage factors.

- Purchase/ active ratio: This ratio is also known as the next buy or the opening of a new service and calculated by (number of buying new services purchased/ number of buying existing services purchased) in the last 12 months.

- Drop ratio: The ratio expresses the percentage of the customer's decision to cancel a product that is characterized by a non-ending status and calculated by (number of drop/cancelled services/ existing services offered by bank) in the last 12 months.

- Retention ratio: The ratio expresses the percentage of the respond or active customer to buy the new services in the last 12 months and calculated by (the number of active customers/ number of total customers).

- New customer vision: The experimental study will be used to measure the difference between the customer vision towards the bank's services and the products after introducing KDD techniques and the customer opinion in the services that offered based on implementing KDD results.

\section{Conclusions and Further work}

In this paper, we proposed a framework for studying the effect of KDD on CRM in the Egyptian banking sector. We believe that the KDD process and the applications may perform a significant role in Egyptian banks to improve CRM, in particular for customer retention. Our belief is supported by the results of a field survey at the largest Egyptian bank that indicated that: 
- most of the bank's customers are neither satisfied in dealing with the bank, nor have any loyalty towards the bank, but do feel safe in dealing with the bank;

- the bank's CRM department is not satisfied with the existing service systems; and

- the IT department is not satisfied with the existing service level they offer to other employees' bank through all services, and supports the introduction of the new techniques.

These problems are could typically be solved by the adoption of KDD. The next step is to analyze the effect of adopting KDD in the banking sector in Egypt according to the conceptual framework. We expect the first results to be available when the bank has implemented KDD by the end of 2006 .

\section{References}

[1] OECD, A New Economy? - The Role of Innovation and Information Technology in Recent OECD Economic Growth, DSTI/IND/STP/ICCP, No.1, 2000.

[2] Porter, M. and S. Stern, Innovation: Location Matters, Sloan Management Review, 2001, pp. 28-37.

[3] Devedzic, V., Knowledge Discovery and Data Mining, School of Business Administration, University of Belgrade, Yugoslavia, 1998, pp.1-24.

[4] Stonman, Paul, Financial Factors and the Inter Firm Diffusion of New Technology: A Real Option Model, University of Warwick EIFC Working Paper No.8, 2001.

[5] Dixit, Avinah, and Robert Pindyck, Investment Under Uncertainty, (Princeton, New Jersey: Princeton University Press, 1994).

[6] Hall, Bronwyn H and Khan, Beethika, Adoption of New Technology, University of California, Berkeley, Department of Economics, VCB, Working Paper No. E03-330, 2003, pp. 1-16.

[7] Vitria, Technology, Inc., Maximizing the Value of Customer Information Across Your Financial Services Enterprise, White Paper, 2002, pp.1-10.

[8] El-Shazly, Alaa, Incentive-Based Regulations and Bank Restructuring in Egypt, Cairo University, Egypt, 2001, pp.1-24.

[9] Ragunathan, V., Financial Deregulation and Integration: An Australian Perspective, Journal of Economics and Business, 1999, pp. 505-514.

[10] Berger, A. N. and D. B. Humphrey, The dominance of inefficiencies over scale and product mix economies in banking, Joumal of Monetary Economics, Vol.28, 1991 pp.117-148.

[11] Berger, A. N., W. C. Hunter, and S. G. Timme, The Efficiency of Financial Institutions: A Review and Preview of Research Past, Present, and Future, Joumal of Banking and Finance Vol.17, 1993, pp. 221-249.

[12] Harrison Tina, Financial Service Marketing, (Pearson Education Limited, 2000).

[13] Davis, F. D., Perceived Usefulness, Perceived Ease of Use and User Acceptance of Information Technology, MIS Quarterly, Vol.13 (3), 1989, pp. 319-340. 